\title{
Acardia anceps: the monster twin; twin reversed arterial perfusion (TRAP) syndrome
}

\author{
Shazia Khan ${ }^{1 *}$, Tina Singh ${ }^{2}$, Gunadhar Maiti ${ }^{3}$
}

\begin{abstract}
${ }^{1}$ Department of Obstetrics and Gynecology, INHS Asvini, Mumbai, Maharashtra, India
${ }^{2}$ Department of Obstetrics and Gynecology, INHS Kalyani, Vizag, Andhra Pradesh, India

${ }^{3}$ Department of Obstetrics and Gynecology, CHEC, Kolkata, West Bengal, India
\end{abstract}

Received: 10 September 2018

Accepted: 05 October 2018

\author{
*Correspondence: \\ Dr. Shazia Khan, \\ E-mail: drshaziakhan@gmail.com
}

Copyright: (c) the author(s), publisher and licensee Medip Academy. This is an open-access article distributed under the terms of the Creative Commons Attribution Non-Commercial License, which permits unrestricted non-commercial use, distribution, and reproduction in any medium, provided the original work is properly cited.

\begin{abstract}
Twin reversed arterial perfusion (TRAP) sequence is an extremely rare complication of monochorionic multi-foetal pregnancy, occurring once in 35,000 births. It is characterized by a malformed foetus without a heart being perfused by a structurally normal (pump) twin via an artery-to-artery anastomosis in a reverse direction. We report one such case where ultrasound imaging revealed monochorionic twin pregnancy with a viable, normal-appearing first twin and a structurally aberrant second twin with absent cardiac activity. The patient was monitored with two weekly ultrasonography and Doppler ultrasound examination to ascertain the well-being of the pump twin. She delivered successfully at term a normal live baby and an acardius anceps foetus. The perinatal mortality of the pump twin ranges from 35 to 55\%; making it essential to diagnose the presence of a pump twin at an early gestational age through improved imaging techniques to plan effective intervention at appropriate time.
\end{abstract}

Keywords: Acardia anceps, Acardia twin, Monochorionic twin, TRAP sequence

\section{INTRODUCTION}

Acardiac monster twin go back in history when they were first described by Beneditti in $1533 .{ }^{1}$ A rare fetopathic complication of Monochorionic twin pregnancy TwinReversed Arterial Perfusion (TRAP sequence) is also known as Acardius or Chorioangiopagus parasiticus or Acardia parabioticus. It occurs in $1 \%$ of monochorionic twin pregnancies and in 1 in 35,000 pregnancies. ${ }^{2,3}$ The risk of recurrence was estimated 1:10,000

In TRAP sequence, one twin is usually developmentally normal (pump twin) and the other twin has a serious condition, either missing a heart (acardiac) or a head (acephalic) or both, that prevents it from surviving on its own. The acardiac/acephalic twin receives all of its blood from the normal or "pump" twin. The term "reversed perfusion" is used to describe this scenario because blood enters the acardiac/acephalic twin through reversed flow through its umbilical artery and exits through the umbilical vein, which is opposite to the normal blood supply of the fetus. Here we describe one such case of Acardia anceps managed conservatively with a successful outcome for the pump twin.

\section{CASE REPORT}

A 28-year-old G3P1L1A1 lady presented at 25 weeks period of gestation for routine antenatal care. A level II scan revealed a diamniotic monochorionic twin pregnancy with single placenta. Twin A was morphologically normal with a mean gestational age of 25 weeks, but Twin B showed absence of cardiac activity with biometry corresponding 17 weeks period of gestation and grossly dysmorphic features of poorly formed fetal head, neck, spine and thorax and diffuse subcutaneous edema with multiple cystic areas (Figure $1)$. 

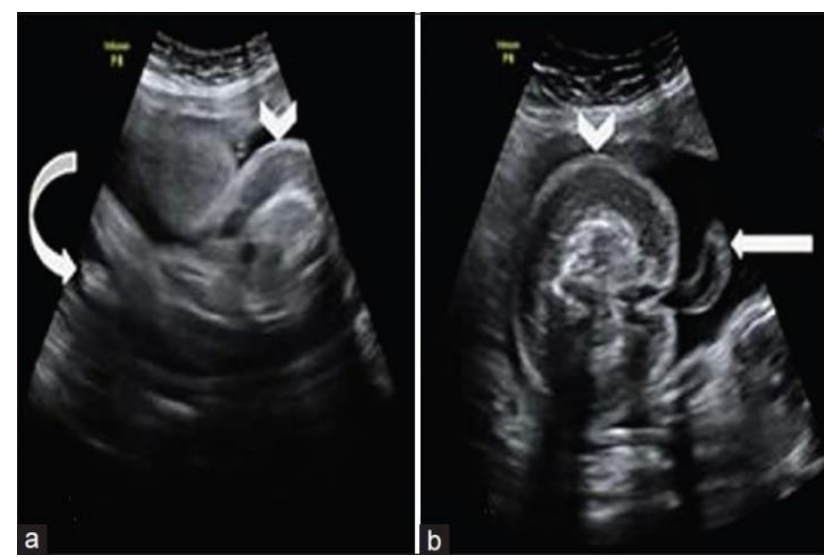

Figure 1: Transabdominal ultrasonography scans (a) oblique and (b) axial views of abnormal fetus show well-developed lower limbs (curved arrow in a) with feet and umbilical cord (arrow in b), and diffuse, gross soft tissue edema.

A possible diagnosis of single fetal demise and associated twin reversed arterial perfusion (TRAP) was considered. Couple were counselled about possible adverse outcomes and advised follow up at a center with availability of interventional facility of radiofrequency ablation. They were however willing to continue the pregnancy without any intervention at our hospital. The lady was followed up in OPD as a high-risk case 2 weekly. She was given two doses of Inj Betamethasone 12mg intramuscularly 24 hourly at 29 weeks. A color doppler and ultrasonography at 30 weeks revealed normal growth of Twin A with no evidence of cardiomegaly or polyhydramnios. Twin B was acardiac with normal appearing lower limb and upper extremity deformity. There was no reversal of flow in umblical artery doppler study (UA S/D =2.81). Patient went into preterm labour at 34 weeks. Vaginal trial of labour was given. Twin A was cephalic and a $2.3 \mathrm{Kg}$ female with no gross congenital anomaly and normal Apgar was delivered vaginally (Figure 2).

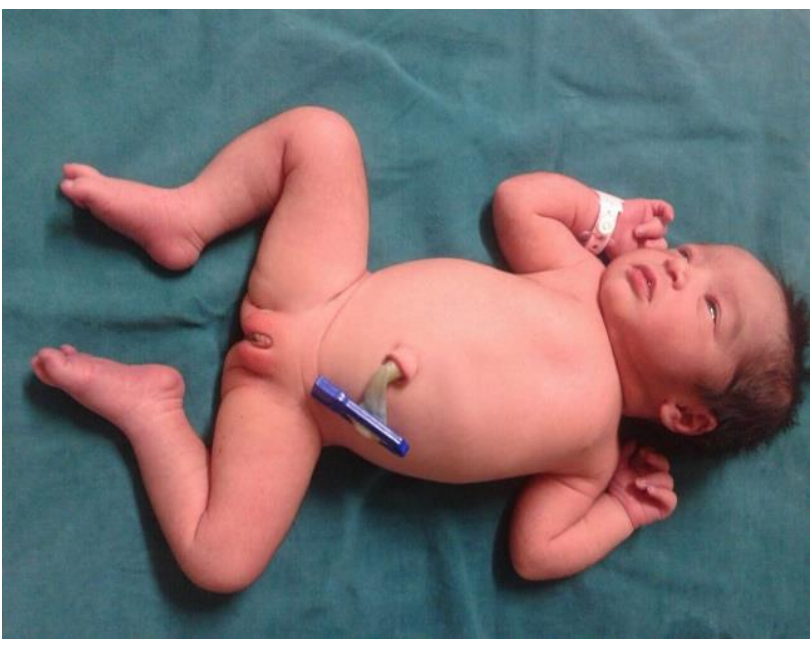

Figure 2: Normal appearing pump twin.

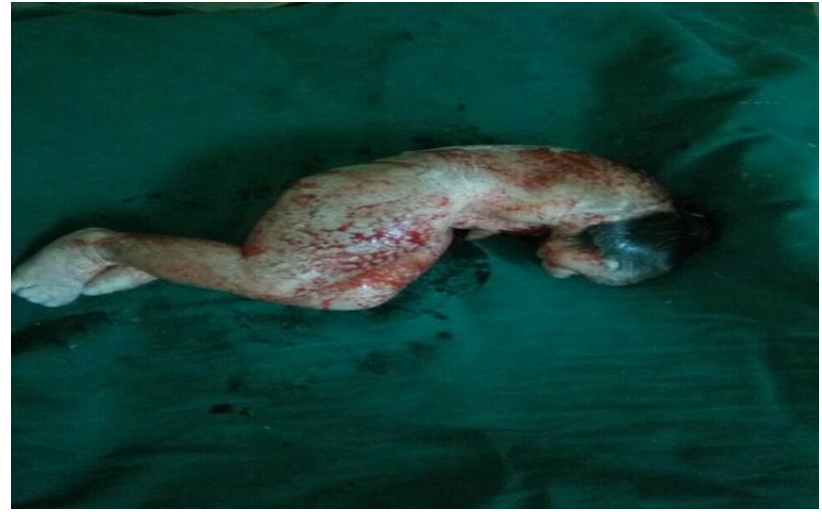

Figure 3: Acardia anceps twin represent absent upper limbs.

Twin B was delivered via assisted breech delivery. It had well developed lower limbs with presence of rudimentary male genitalia and absent cardiac activity. Upper limb was absent, and a partially developed head and neck was present (Figure 3 and 4).

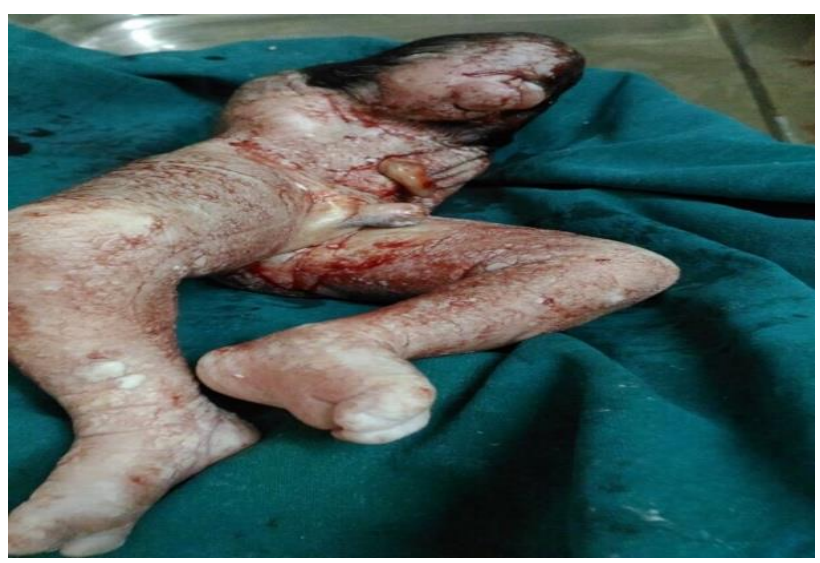

Figure 4: Acardia anceps twin representing partially developed head and face, rudimentary male genitalia.

It weighed $1 \mathrm{~kg}$. Diagnosis of Acardia Anceps was made. A single monochorionic diamniotic placenta with two cords $-16 \mathrm{~cm}$ and a thin $9 \mathrm{~cm}$ was present (Figure 5).

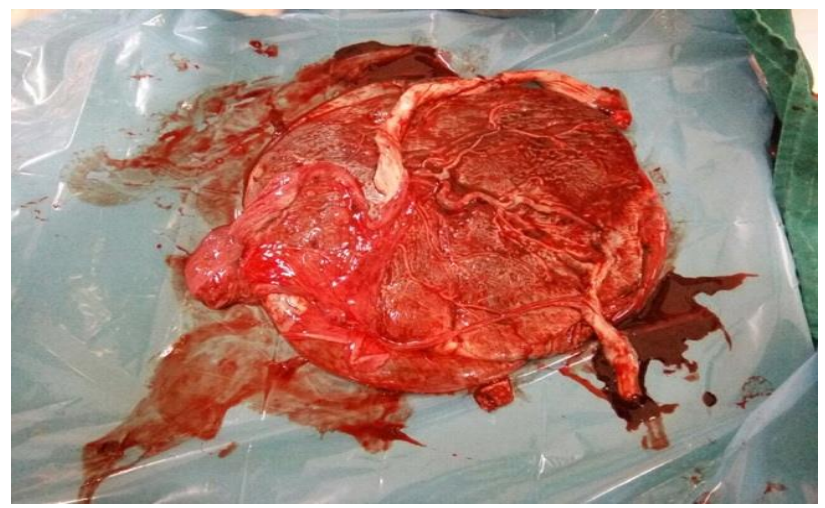

Figure 5: Monochorionic placenta with two cords. 
Couple refused autopsy and karyotyping of Acardiac twin. An infantogram of acardia twin revealed partially formed skull and facial bones. Spine was not visualized in total. Both femurs and pelvic girdle were well developed with partially developed upper limbs. (Figure 6) Post-natal period was uneventful. Twin A was evaluated for cardiomegaly and ascites by neonatologist and was discharged on Post-natal day 6.

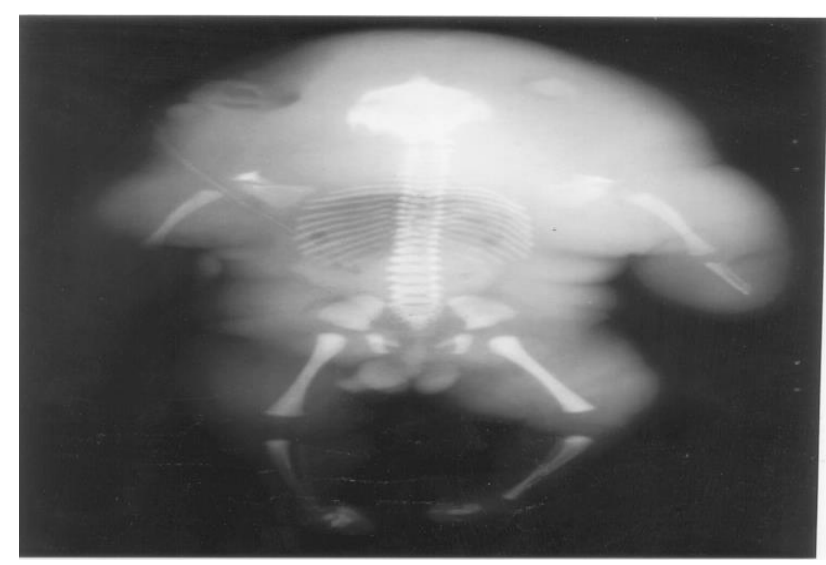

Figure 6: Infantogram of Acardia twin-partially formed skull, facial bones.

\section{DISCUSSION}

Twin Reversed Arterial Perfusion sequence is a bizarre congenital anomaly associated with monozygotic multiple pregnancy. It is a result of formation of abnormal placental anastomosis leading to development of a malformed fetus with either an absent or rudimentary heart (acardius) along with abnormality of other structures (recipient twin). The Pump Twin is usually developmentally normal though features of cardiac overload and polyhydramnios do develop in later pregnancy in them. Twin reversed arterial perfusion (TRAP) was defined by Greenwald in $1942 .{ }^{1}$ Around 500 cases have been reported since then. The etiopathogenesis of TRAP sequence is hypothesized as a large artery to artery intraplacental shunt often accompanied by a vein to vein shunt. The single shared placenta has within it the arterial perfusion pressure of the donor twin exceeding that of the recipient twin who thus receives reverse blood flow of deoxygenated arterial blood from its co-twin. The umbilical arteries carry this used blood in the recipient twin which preferentially goes to its iliac vessels. Thus, only the lower body is perfused and disrupted growth and development of the upper body results. ${ }^{2}$

Das presented the first classification of acardiac twins in 1902 and this was later modified by Napolitani. ${ }^{3}$ The distinction criteria are morphological - the presence or absence of head, body and cardiac tissue

- Acardiac Anceps: There is a relatively welldeveloped fetus. Parts of the brain, skeleton of face, meninges and scalp hairs are present.
- Acardiac acephalus: The head and thoracic organs are absent.

- Acardiac acormus: Rarest type and is also called as bodyless head.

- Acardiac amorphus: This lesion has lump of tissue covered by skin. It contains bone, cartilage, fat and muscles

Two-third of acardiacs are acephalic, which is the most common variety, and they are usually female. ${ }^{4}$ The presence of discordant sex in the monozygotic twins in our case report can be explained as a sequence of probable presence of heterokayotype or chimerism of sex chromosomes. The acardiac twin though phenotypically male could have had chromosomal aberration which a karyotyping would have assisted in diagnosing.

A monochorionic, malformed fetus with cystic hygroma, generalized edema and an absent cardiac pulsation with a non-functioning heart on ultrasonography should raise suspicion towards the possibility of acardiac twinning.Sonography findings of discordant growth along with color Doppler finding of reverse flow in the umbilical artery is diagnostic of an acardiac twin. ${ }^{5}$ But the diagnosis is not always simple. The most frequent confusion is with anencephaly or with fetal demise of one twin. It is easy to erroneously diagnose fetal death in these cases because of the absence of cardiac motion and movement in the acardiac twin. MRI maybe useful as an adjunct in already identified cases to assess the presence of retrograde blood flow in the acardiac fetus and umbilical artery. ${ }^{6}$ Early diagnosis reduces the risk of complication, as the perinatal mortality rate is reported to be $50-70 \%$ for donor twin.

The management of monochorionic Acardiac twin pregnancy is complex and challenging as the continuous growth of the acardiac fetus is deleterious to the healthy pump twin. There can be polyhydramnios, cardiac failure due to overload, prematurity and even death of the pump twin in up to $50 \%$ of cases. ${ }^{7}$ Optimal management is often controversial. Use of expectant management versus interventional techniques antenatally, is still debated. Various modalities of management include extreme methods like termination of pregnancy and hysterotomy for selective removal of anomalous twin along with conservative approach of serial ultrasounds to monitor for signs of decompensation, medical management of polyhydramnios or by serial amniocentesis. Platt et al. in 1983 first came up with the solution of occluding the circulation to the acardiac twin as the definitive treatment. ${ }^{8}$ This thought process evolved into invasive interventional methods of cord occlusion techniques or intrafetal ablation. Cord occlusion is attempted by embolization, laser coagulation, cord ligation, bipolar and monopolar diathermy. Intrafetal ablation is performed with radiofrequency, alcohol, monopolar diathermy and interstitial laser. ${ }^{9}$ Utilization of invasive treatment should be restricted to those pregnancies where the pump twin is at a significant risk of cardiac insufficiency, prematurity, 
polyhydramnios or death and the acardiac twin has a rapid growth of or evidence of substantial blood flow perfusion through the umbilical vessel supplying the parasitic mass. ${ }^{10}$

\section{CONCLUSION}

TRAP sequence is an extremely rare complication of monochorionic multiple gestation. Timely antenatal diagnosis is absolutely essential for better prognosis. A radiologist should have a high index of suspicion while doing ultrasonography if there is monochorionic twin pregnancy with a foetus which, in spite of absence of cardiac activity, continues to grow. The prognosis for pump twin has improved as this condition can now be picked up by ultrasound and Doppler as early as first trimester. Though many patients can benefit from conservative treatment, recent trend toward using minimally invasive treatment modalities for the vascular anastomosis has been a boon in improving the outcome of the pump twin.

\section{Funding: No funding sources}

Conflict of interest: None declared

Ethical approval: Not required

\section{REFERENCES}

1. Blaicher W, Repa C, Schaller A. Acardiac twin pregnancy: associated with trisomy 2: case report. Hum Reprod. 2000;15(2):474-5.

2. Cunningham FG, Leveno KJ, Bloom SL, Hauth JC, Rouse DJ, Spong CY. Williams Obstetrics 23rd Edition 2010 McGraw Hill, New York. 872.
3. Napolitani FD, Schreiber I. The acardiac monster. Am J Obstet Gynecol. 1960;80(3):582-589

4. Dhall U, Kayalvizi I, Merg S. Acardius Acephalus. Monster-A Case Report. J Anat Soc India .2005;54(1):26-8.

5. Ishimatsu J, Nakanami H, Hamada T, Yakushiji M. Color and pulsed Doppler ultrasonography of reversed umbilical blood flow in an acardiac twin. Asia Oceania J Obstet Gynaecol. 1993;19(3):271-5

6. Hata N, Wada T, Kashima K, Okada Y, Unno N, Kitagawa M, Chiba T. Nongated fetal MRI of umbilical blood flow in an Acardiac twin. Pediatric Radiology 2005;35(8):826-9

7. Moore TR, Gale S, Benirschke K. Perinatal outcome of forty-nine pregnancies complicated by acardiac twinning. Am J Obstet Gynecol. 1990;163(3):90712.

8. Platt LD, DeVore GR, Bieniarz A, Benner P, Rao R. Antenatal diagnosis of acephalus acardia: a proposed management scheme. Am J Obstet Gynecol. 1983;146(7):857-9.

9. Tan TY, Sepulveda W. Acardiac twin: A systematic review of minimally invasive treatment modalities. Ultrasound Obstet Gynecol. 2003;22(4):409-19.

10. Sullivan AE, Varner MW, Ball RH, Jackson M, Silver RM. The management of acardiac twins: a conservative approach. Am J Obstet Gynecol. 2003;189(5):1310-3.

Cite this article as: Khan S, Singh T, Maiti G. Acardia anceps: the monster twin; twin reversed arterial perfusion (TRAP) syndrome. Int J Reprod Contracept Obstet Gynecol 2018;7:4775-8. 